\title{
DETERMINAN KEPATUHAN PERAWAT DALAM PENERAPAN KEWASPADAAN STANDAR DI RUMAH SAKIT UMUM DI KOTA DENPASAR TAHUN 2020
}

\author{
I Gusti Agung Ngurah Arya Pradnyana, Partha Muliawan* \\ Program Studi Sarjana Kesehatan Masyarakat Fakultas Kedokteran Universitas Udayana \\ *Email: partha.muliawan@gmail.com
}

\begin{abstract}
ABSTRAK
Kewaspadaan standar adalah praktik pencegahan infeksi minimum yang berlaku untuk semua perawatan pasien, terlepas dari status infeksinya dengan tujuan untuk melindungi dan mencegah tenaga perawatan kesehatan menyebarkan infeksi kepada pasien. Penelitian ini bertujuan untuk mengetahui determinan kepatuhan perawat dalam penerapan kewaspadaan standar di Rumah Sakit Umum di Kota Denpasar. Desain penelitian yang digunakan adalah deskriptif analitik dengan metode kuantitatif dan rancangan cross-sectional. Sampel dari penelitian ini adalah perawat di Rumah Sakit Umum di Kota Denpasar sebanyak 76 responden dari 260 perawat yang terpilih menggunakan metode systematic random sampling. Penelitian dilakukan selama bulan April Tahun 2020. Instrumen pengumpulan data menggunakan kuesioner dan lembar observasi. Analisis data dilakukan secara univariabel, bivariabel dan multivariabel. Hasil penelitian menunjukkan sebanyak 59,21\% responden patuh dalam menerapkan pedoman kewaspadaan standar. Terdapat hubungan bermakna antara pengetahuan, iklim keselamatan, ketersediaan sarana dan fasilitas, serta informasi dan pelatihan dengan kepatuhan penerapan kewaspadaan standar $(\mathrm{p}<0,05)$. Analisis multivariabel menunjukkan bahwa variabel ketersediaan sarana dan fasilitas merupakan variabel yang paling memiliki pengaruh paling kuat dengan penerapan kewaspadaan standar. Sebagai upaya meningkatkan kepatuhan, agar selalu menjadikan perlindungan pekerja terhadap pajanan penyakit infeksi sebagai hal yang harus diutamakan melalui pemenuhan kebutuhan tersedianya sarana dan fasilitas yang berhubungan dengan penerapan kewaspadaan standar.
\end{abstract}

Kata Kunci: Kepatuhan, Kewaspadaan Standar, Penyakit Infeksi, Perawat, Rumah Sakit.

\begin{abstract}
Standard Precautios are the minimum infection prevention practices that apply to all patient care, regardless of suspected or confirmed infection status of the patient, in any setting where healthcare is delivered. The aim of this research is to determine the factors associated with compliance to standard precaution among nurses in Public Hospital Denpasar City. The research design is descriptive-analytical with quantitative method based cross-sectional study. Sample of this research are 76 from 260 nurses in Public Hospital Denpasar City that selected based on systematic random sampling. This research has been conducted during April 2020. The instrument of collecting data use questionnarie and obervations sheets. Data is analyzed in univariable, bivariable, and multivariable. The result of this study showed that the proportion of nurses compliance with standard precaution was 59,21\%. The research also showed that variable knowledge, safety climate, facilities availability, information and training positively correlated with standard precautions compliance $(p<0,05)$. Multivariable analysis showed that the variable facilities availability is the variable most closely associated with the application of standard precautions. To improve compliance, nurses expose protection of infectious disease should be a priority program through fulfill the needs for the availability of facilities that related to the application of standard precautions compliance.
\end{abstract}

Key Words: Compliance, Standard Precautions, Infectious Diseases, Nurses, Hospital

\section{PENDAHULUAN}

Penyakit infeksi terkait pelayanan kesehatan kini telah dikenal dengan istilah Healthcare Associated Infection (HAIs) (Krisnata, 2016). Healthcare Associated Infection (HAIs) tidak hanya sebatas infeksi kepada pasien, namun dapat juga kepada petugas kesehatan dan pengunjung yang tertular pada saat berada di dalam lingkungan fasilitas pelayanan kesehatan (Kemenkes RI, 2017). Petugas kesehatan tentunya dapat terpajan penularan penyakit infeksi blood-borne seperti HIV, hepatitis B, dan hepatitis C dimana sumbernya berasal dari benda 
terkontaminasi, jarum suntik bekas pakai dan benda tajam lainnya (Sahara, 2011).

World Health Organization (WHO) memperkirakan pada petugas kesehatan sedikitnya terjadi tiga juta pajanan terhadap darah atau jaringan tubuh pada setiap tahunnya. Di Indonesia, pekerja rumah sakit (RS) berisiko 1,5 kali lebih besar dari golongan pekerjaan lain. Probabilitas penularan HIV setelah terkena tusukan jarum suntik yang terkontaminasi HIV 4:1000, HBV 27-37:100, dan HCV 310:100 (Kemenkes RI, 2010).

Pedoman Kewaspadaan Universal dibentuk oleh Centers for Disease Control and Prevention (CDC) pada tahun 1987. Dalam kewaspadaan universal tersebut, petugas kesehatan memiliki prinsip bahwa setiap pasien berpotensi menularkan/tertular penyakit infeksi (Efstathiou et al., 2011). Pedoman tersebut kemudian diadaptasi menjadi Pedoman Kewaspadaan Standar disusun oleh Health Infections Control Practice Advisory Committee (HICPAC) yang merupakan kombinasi dari kewaspadaan universal dan body substance isolation. Kewaspadaan standar memiliki prinsip bahwa semua darah, cairan tubuh, sekresi, ekskresi, kecuali keringat, dan selaput mukosa yang mengandung agen infeksius dapat menular (CDC, 2007).

Kepatuhan terhadap kewaspadaan standar dipengaruhi oleh beberapa faktor. Berdasarkan penelitian yang dilakukan oleh Sahara (2011), sebesar 52,4\% perawat dan bidan memiliki tingkat kepatuhan baik dalam penerapan kewaspadaan universal/standar, dimana iklim keselamatan kerja, pelatihan, dan ketersediaan alat pelindung diri merupakan faktor yang berpengaruh secara signifikan terhadap kepatuhan penerapan kewaspadaan universal/standar. Penelitian yang dilakukan oleh Yuliana (2012) sebesar $66,7 \%$ perawat memiliki perilaku patuh dalam penerapan kewaspadaan standar, dimana faktor yang berhubungan secara signifikan antara lain pengetahuan, hambatan penerapan kewaspadaan standar, ketersediaan sarana dan fasilitas serta informasi dan pelatihan.

Perawat adalah salah satu profesi di bidang kesehatan yang memiliki peranan penting dalam memberikan pelayanan kesehatan dan juga merupakan tenaga kesehatan dengan jumlah paling banyak dan dengan durasi paling lama kontak dengan pasien sehingga sangat berisiko dengan pekerjaanya, namun banyak perawat yang tidak menyadari terhadap risiko keselamatan dan kesehatan kerja (K3) (Runtu et al., 2013). Penelitian yang dilakukan oleh Mapanawang et al., (2017) menunjukkan bahwa beban kerja perawat yang berat memiliki peluang sebesar 2,6 kali mengalami luka tusuk jarum suntik dibandingkan dengan beban kerja yang ringan.

Berdasarkan data yang diperoleh di Rumah Sakit Umum di Kota Denpasar, masih terdapat kecelakaan kerja tertusuk jarum berturut-turut sebanyak 9 kasus, 9 kasus, dan 10 kasus dari tahun 2017 hingga tahun 2019. Selain itu, ada beberapa kasus ketidakpatuhan penerapan kewaspadaan standar seperti ditemukannya alat medis yang telah digunakan seperti jarum, kemasan obat, dan ampul obat yang bercampur dengan linen dari salah satu 
unit kerja. Berdasarkan latar belakang tersebut, penulis ingin mengetahui determinan kepatuhan perawat dalam Penerapan kewaspadaan standar di Rumah Sakit Umum di Kota Denpasar.

\section{METODE PENELITIAN}

Penelitian ini merupakan penelitian deskriptif analitik dengan menggunakan rancangan cross-sectional, yang dilakukan di salah satu rumah sakit umum di Kota Denpasar selama bulan April Tahun 2020. Jumlah sampel dalam penelitian ini yaitu 76 responden dari populasi sebanyak 260 perawat yang memenuhi kriteria inklusi yaitu perawat yang sudah bekerja minimal 1 tahun dan perawat yang memberikan tindakan kesehatan kepada pasien secara langsung. Sedangkan kriteria eksklusi yaitu perawat yang hanya bekerja sebagai manajemen ruangan atau manajemen rumah sakit.

Pengumpulan data dilakukan dengan memberikan kuesioner dan lembar observasi kepada perawat yang berisi karakteristik demografi, faktor terkait pekerjaan, faktor organisasi, dan kepatuhan perawat dalam penerapan kewaspadaan standar. Kuesioner yang digunakan diadaptasi dari penelitian Sahara (2011) mengenai perilaku kepatuhan dan penelitian Yotlely (2019) mengenai komponen-komponen variabel bebas yang sudah teruji validitas dan reabilitasnya.

Pengkategorian variabel dalam penelitian ini menggunakan skor pada variabel pengetahuan tentang kewaspadaan standar (KS), hambatan dalam penerapan kewaspadaan standar serta ketersediaan sarana dan fasilitas dan menggunakan median pada variabel persepsi tentang risiko, beban kerja, iklim keselamatan, serta informasi dan pelatihan. Data dianalisis secara univariabel dengan mendeskripsikan distribusi frekuensi dan proporsi masing-masing variabel. Analisis bivariabel dilakukan dengan uji chi square dengan tingkat kepercayaan 95\% $(\alpha=0,05)$ untuk mengetahui hubungan antara satu variabel bebas dengan satu variabel tergantung. Analisis multivariabel dilakukan dengan uji multiple logistic regression dengan menyeleksi variabel yang memiliki nilai $\mathrm{p}<0,25$ pada analisis bivariabel untuk mengetahui variabel bebas yang memiliki pengaruh paling kuat terhadap variabel tergantung.

\section{HASIL}

Berdasarkan hasil analisis univariabel menunjukkan bahwa umur responden berkisar antara 26-60 tahun dengan rata-rata umur 35 tahun $(\mathrm{SD}=8)$. Proporsi responden terbanyak terdapat pada kelompok umur 30-39 tahun, mayoritas berjenis kelamin perempuan, dan dengan tingkat pendidikan paling banyak dengan latar belakang S1+Ners. Mayoritas responden telah patuh dalam menerapkan kewaspadaan standar. Pada faktor terkait pekerjaan, mayoritas responden memiliki pengetahuan tentang kewaspadaan standar dan persepsi tentang risiko baik, mayoritas memiliki hambatan dalam penerapan kewaspadaan standar dan dengan beban kerja yang tinggi. Pada faktor organisasi, mayoritas responden dengan iklim keselamatan baik, unit 
kerjanya tersedia sarana dan fasilitas yang lengkap serta telah mendapatkan informasi dan pelatihan secara kompeherensif.
Adapun rinciannya dapat dilihat pada Tabel 1.

Tabel 1. Analisis Univariabel

\begin{tabular}{|c|c|c|}
\hline Karakteristik Demografi & Frekuensi (n) & Proporsi (\%) \\
\hline \multicolumn{3}{|l|}{ Umur } \\
\hline 20-29 Tahun & 22 & 28.95 \\
\hline 30-39 Tahun & 38 & 50.00 \\
\hline 40-49 Tahun & 7 & 9.21 \\
\hline$\geq 50$ Tahun & 9 & 11.84 \\
\hline \multicolumn{3}{|l|}{ Jenis Kelamin } \\
\hline Laki-laki & 31 & 40.79 \\
\hline Perempuan & 45 & 59.21 \\
\hline \multicolumn{3}{|l|}{ Tingkat Pendidikan } \\
\hline D3 & 37 & 48.68 \\
\hline S1 + Ners & 39 & 51.32 \\
\hline Faktor Terkait Pekerjaan & Frekuensi (n) & Proporsi (\%) \\
\hline \multicolumn{3}{|l|}{ Pengetahuan Tentang KS } \\
\hline Baik & 62 & 81.58 \\
\hline Kurang Baik & 14 & 18.42 \\
\hline \multicolumn{3}{|l|}{ Persepsi Tentang Risiko } \\
\hline Baik & 40 & 52.63 \\
\hline Tidak Baik & 36 & 47.37 \\
\hline \multicolumn{3}{|l|}{ Hambatan dalam Penerapan KS } \\
\hline Tidak Ada Hambatan & 48 & 63.16 \\
\hline Ada Hambatan & 28 & 36.84 \\
\hline \multicolumn{3}{|l|}{ Beban Kerja } \\
\hline Rendah & 35 & 46.05 \\
\hline Tinggi & 41 & 53.95 \\
\hline Faktor Organisasi & Frekuensi (n) & Proporsi (\%) \\
\hline \multicolumn{3}{|l|}{ Iklim Keselamatan } \\
\hline Baik & 44 & 57.89 \\
\hline Tidak Baik & 32 & 42.11 \\
\hline \multicolumn{3}{|l|}{ Ketersediaan Sarana dan Fasilitas } \\
\hline Lengkap & 47 & 61.84 \\
\hline Tidak Lengkap & 29 & 38.16 \\
\hline \multicolumn{3}{|l|}{ Informasi dan Pelatihan } \\
\hline Kompeherensif & 56 & 73.68 \\
\hline Kurang Kompeherensif & 20 & 26.32 \\
\hline Kepatuhan dalam Penerapan KS & Frekuensi (n) & Proporsi (\%) \\
\hline Patuh & 45 & 59.21 \\
\hline Kurang Patuh & 31 & 40.79 \\
\hline
\end{tabular}


Tabel 2 menunjukkan bahwa pada faktor terkait pekerjaan, variabel pengetahuan saja yang memiliki hubungan bermakna dengan kepatuhan perawat dalam penerapan kewaspadaan standar $(p<0,05)$ yang mana berdasarkan nilai $P R$, responden yang memiliki pengetahuan baik 1,8 kali lebih patuh dalam menerapkan kewaspadaan standar. Seluruh variabel pada faktor organisasi memiliki hubungan yang bermakna terhadap kepatuhan perawat dalam penerapan kewaspadaan standar $(\mathrm{p}<0,05)$ yang mana berdasarkan nilai PR, menunjukkan bahwa iklim keselamatan yang baik, ketersediaan sarana dan fasilitas yang lengkap, serta informasi dan pelatihan yang kompeherensif masingmasing 1,6; 1,7; 1,9 kali lebih patuh dalam menerapkan kewaspadaan standar (KS).

Tabel 2. Analisis Bivariabel

\begin{tabular}{|c|c|c|c|c|c|c|}
\hline \multirow[b]{2}{*}{ Variabel } & \multicolumn{2}{|c|}{ Kepatuhan Penerapan KS } & \multirow[b]{2}{*}{$\begin{array}{l}\text { Total } \\
\text { n (\%) }\end{array}$} & \multirow[b]{2}{*}{ PR } & \multirow[b]{2}{*}{$95 \% \mathrm{CI}$} & \multirow[b]{2}{*}{$\mathbf{p}$} \\
\hline & $\begin{array}{c}\text { Patuh n } \\
(\%)\end{array}$ & $\begin{array}{c}\text { Kurang Patuh } \\
\text { n (\%) }\end{array}$ & & & & \\
\hline \multicolumn{7}{|l|}{ Umur } \\
\hline$<30$ Tahun & $13(61.90)$ & $8(38.10)$ & $21(100)$ & 0.9 & $(0.63-1.40)$ & 0.768 \\
\hline$\geq 30$ Tahun & $32(52.18)$ & $23(41.82)$ & $55(100)$ & & & \\
\hline \multicolumn{7}{|l|}{ Jenis Kelamin } \\
\hline Laki-laki & $22(70.97)$ & $9(29.03)$ & $31(100)$ & 0.7 & $(0.50-1.04)$ & 0.083 \\
\hline Perempuan & $23(51.11)$ & $22(48.89)$ & $45(100)$ & & & \\
\hline \multicolumn{7}{|l|}{ Tingkat Pendidikan } \\
\hline D3 & $25(67.57)$ & $12(32.43)$ & $37(100)$ & 0.8 & $(0.52-1.11)$ & 0.149 \\
\hline S1+Ners & $20(51.28)$ & $19(48.72)$ & $39(100)$ & & & \\
\hline \multicolumn{7}{|l|}{ Pengetahuan KS } \\
\hline Baik & $40(64.52)$ & $22(35.48)$ & $62(100)$ & 1.8 & $(0.87-3.74)$ & 0.048 \\
\hline Kurang Baik & $5(35.71)$ & $9(64.29)$ & $14(100)$ & & & \\
\hline \multicolumn{7}{|l|}{ Persepsi Tentang } \\
\hline Risiko & $26(65.00)$ & $14(35.00)$ & $40(100)$ & 1.2 & $(0.84-1.81)$ & 0.279 \\
\hline Baik & $19(52.78)$ & $17(47.22)$ & $36(100)$ & & & \\
\hline \multicolumn{7}{|l|}{ Tidak Baik } \\
\hline \multicolumn{7}{|l|}{ Hambatan Penerapan } \\
\hline KS & $29(60.42)$ & $19(39.58)$ & $48(100)$ & 1.1 & $(0.71-1.57)$ & 0.779 \\
\hline Tidak Ada Hambatan & $16(57.14)$ & $12(42.86)$ & $28(100)$ & & & \\
\hline \multicolumn{7}{|l|}{ Ada Hambatan } \\
\hline \multicolumn{7}{|l|}{ Beban Kerja } \\
\hline Rendah & $20(57.14)$ & $15(42.86)$ & $35(100)$ & 0.9 & $(0.64-1.37)$ & 0.734 \\
\hline Tinggi & $25(60.98)$ & $16(39.02)$ & $41(100)$ & & & \\
\hline \multicolumn{7}{|l|}{ Iklim Keselamatan } \\
\hline Baik & $31(70.45)$ & $13(29.55)$ & $44(100)$ & 1.6 & $(1.04-2.49)$ & 0.019 \\
\hline Tidak Baik & $14(43.75)$ & $18(56.25)$ & $32(100)$ & & & \\
\hline \multicolumn{7}{|l|}{ Informasi dan } \\
\hline Pelatihan & $37(66.07)$ & $19(39.93)$ & $56(100)$ & 1.7 & $(0.94-2.92)$ & 0.042 \\
\hline Kompeherensif & $8(40.00)$ & $12(60.00)$ & $20(100)$ & & & \\
\hline Kurang Kompeherensif & & & & & & \\
\hline
\end{tabular}




\begin{tabular}{lllllll}
\hline Ketersediaan Sarana & & & & & & \\
Lengkap & $34(72.34)$ & $13(27.66)$ & $47(100)$ & 1.9 & $(1.16-3.14)$ & $\mathbf{0 . 0 0 3}$ \\
Tidak lengkap & $11(37.93)$ & $18(62.07)$ & $29(100)$ & & & \\
\hline
\end{tabular}

Hasil analisis multivariabel pada Tabel 3 menunjukkan bahwa variabel bebas yang memiliki pengaruh paling besar dengan variabel kepatuhan perawat dalam penerapan kewaspadaan standar yaitu ketersediaan sarana dan fasilitas $(\mathrm{OR}=5,31 ; 95 \% \mathrm{CI}=1,530-18,425 ; \mathrm{p}=0,009)$,

Tabel 3. Analisis Multivariabel sesuai dengan nilai odds ratio (OR) yang dihasilkan dalam analisis, responden yang unit kerjanya tersedia sarana dan fasilitas dengan lengkap maka 5,31 kali lebih patuh dalam penerapan kewaspadaan standar di rumah sakit dibandingkan dengan responden yang unit kerjanya tidak tersedia sarana dan fasilitas yang lengkap.

\begin{tabular}{|c|c|c|c|c|}
\hline \multirow{3}{*}{ Variabel } & \multicolumn{4}{|c|}{ Model Akhir } \\
\hline & \multirow{2}{*}{$\begin{array}{c}\text { Adjusted } \\
\text { OR }\end{array}$} & \multicolumn{2}{|c|}{$95 \%$ CI for OR } & \multirow{2}{*}{ p } \\
\hline & & Lower & Upper & \\
\hline \multicolumn{5}{|l|}{ Pengetahuan Tentang KS } \\
\hline Baik & 3.99 & 0.058 & 16.711 & 0.058 \\
\hline Kurang Baik & Reff & & & \\
\hline \multicolumn{5}{|l|}{ Iklim Keselamatan } \\
\hline Baik & 5.15 & 1.549 & 17.094 & 0.007 \\
\hline Tidak Baik & Reff & & & \\
\hline \multicolumn{5}{|l|}{ Informasi dan Pelatihan } \\
\hline Kompeherensif & 2.41 & 0.668 & 8.701 & 0.179 \\
\hline Kurang Kompeherensif & Reff & & & \\
\hline \multicolumn{5}{|c|}{ Ketersediaan Sarana dan Fasilitas } \\
\hline Lengkap & 5.31 & 1.530 & 18.425 & 0.009 \\
\hline Tidak Lengkap & Reff & & & \\
\hline
\end{tabular}

\section{DISKUSI}

Kepatuhan perawat dalam penerapan kewaspadaan standar diperoleh sebanyak 59,21\% responden patuh dalam menerapkan kewaspadaan standar. Hasil penelitian dengan tingkat kepatuhan lebih tinggi didapatkan pada penelitian Mau \& Prayogi (2018) mengenai kepatuhan perawat dalam penerapan universal precaution, sebanyak $62,2 \%$ respondennya patuh terhadap suatu anjuran dan peraturan yang harus ditaati dalam melaksanakan penerapan universal precaution. Hasil penelitian dengan tingkat kepatuhan lebih rendah diperoleh pada penelitian Sahara (2011), dimana 52,4\% responden patuh dalam menerapkan kewaspadaan universal. Keberagaman hasil penelitian ini bisa disebabkan karena jumlah sampel yang digunakan, lokasi rumah sakit, serta adanya faktor-faktor yang berhubungan dengan kepatuhan perawat dalam penerapan kewaspadaan standar.

Variabel yang memiliki pengaruh 
paling kuat dengan kepatuhan perawat dalam penerapan kewaspadaan standar yaitu variabel ketersediaan sarana dan fasilitas, dimana responden yang unit kerjanya tersedia sarana dan fasilitas dengan lengkap akan 5,31 kali lebih patuh dalam menerapkan kewaspadaan standar dibandingkan dengan responden yang unit kerjanya tidak tersedia sarana dan fasilitas dengan lengkap. Variabel yang memiliki pengaruh kuat setelah variabel ketersediaan sarana dan fasilitas yaitu variabel iklim keselamatan, bahwa responden yang iklim keselamatannya baik akan 5,15 kali lebih patuh dibandingkan dengan responden yang iklim keselamatannya tidak baik. Hasil penelitian ini sejalan dengan yang dinyatakan oleh Runtu et al., (2013) dimana variabel persepsi kelengkapan sarana dan prasarana memiliki pengaruh yang paling kuat jika dibandingkan dengan variabel lainnya $\quad(\mathrm{OR}=4,502 ; \quad 95 \% \mathrm{CI}=1,457-13,913$; $\mathrm{p}=0,009)$ dan penelitian Lantu et al., (2015), bahwa variabel yang paling dominan berhubungan dengan penerapan standard precautions yaitu variabel sarana dan prasarana dengan nilai OR terbesar dibandingkan dengan variabel lain (OR=5,928; 95\%CI= 1,838-19,119; $\mathrm{p}=0,003$ ), kemudian disusul oleh variabel iklim keselamatan $(\mathrm{OR}=3,301 ; 95 \% \mathrm{CI}=1,010$ 10,790; $\mathrm{p}=0,048)$.

Berdasarkan hasil tersebut, menunjukkan bahwa variabel ketersediaan sarana dan fasilitas dan iklim keselamatan dapat dijadikan tolak ukur untuk meningkatkan kepatuhan perawat dalam penerapan kewaspadaan standar. Adanya kemudahan dalam mendapatkan ketersediaan alat pelindung diri merupakan faktor yang memegang peranan penting dalam mematuhi kewaspadaan standar (Luo et al., 2010) serta didukung oleh iklim keselamatan yang positif melalui adanya komitmen yang menjadikan keselamatan dan kesehatan kerja rumah sakit (K3RS) sebagai prioritas tentunya akan meningkatkan kesadaran perawat dalam mematuhi pedoman kewaspadaan standar.

Pada analisis bivariabel, menunjukkan terdapat hubungan yang bermakna secara statistik antara variabel pengetahuan dengan kepatuhan dalam penerapan kewaspadaan standar, dimana responden dengan pengetahuan tentang kewaspadaan standar baik 1,8 kali lebih patuh dibandingkan dengan responden dengan pengetahuan kurang baik. Hasil penelitian ini juga sejalan dengan penelitian Gultom et al., (2016) mengenai penerapan kewaspadaan universal yang diketahui bahwa ada hubungan yang bermakna antara pengetahuan dengan penerapan universal precaution oleh perawat di ruang rawat inap penyakit dalam $(p=0,000)$. Pendapat DeJoy (1996) dalam model determinan perilaku kepatuhan untuk perlindungan diri di tempat kerja menyebutkan bahwa pengetahuan merupakan salah satu faktor yang memiliki hubungan dengan perilaku kesehatan seseorang yang salah satunya ada hubungan positif antara pengetahuan dengan praktik kewaspadaan standar.

Analisis bivariabel menunjukkan bahwa ada hubungan yang bermakna 
antara iklim keselamatan dengan kepatuhan perawat, dimana responden dengan iklim keselamatan baik akan lebih patuh 1,6 kali dibandingkan dengan responden dengan iklim keselamatan tidak baik. Hasil penelitian ini konsisten dengan penelitian Lantu et al., (2015), yang menyatakan bahwa terdapat hubungan bermakna antara iklim keselamatan kerja dengan penerapan standard precautions ( $\mathrm{p}=0,006)$. DeJoy et al., (2004) menyebutkan bahwa dalam pelaksanaan iklim keselamatan di tempat kerja salah satunya dipengaruhi oleh faktor prioritas utama di tempat kerja yang berhubungan dengan keselamatan. Hal ini terlihat jelas sesuai hasil analisis bahwa perlindungan pekerja terhadap pajanan penyakit infeksi merupakan hal yang diutamakan oleh pimpinan rumah sakit ini.

Analisis bivariabel menunjukkan bahwa terdapat hubungan yang bermakna antara ketersediaan sarana dan fasilitas dengan kepatuhan perawat dalam penerapan kewaspadaan standar, dimana responden yang unit kerjanya tersedia sarana dan fasilitas dengan lengkap akan lebih patuh 1,9 kali dibandingkan dengan responden yang unit kerjanya tidak tersedia sarana dan fasilitas yang lengkap. Hasil penelitian ini sejalan dengan penelitian Wansuzusino (2019), dimana fasilitas dan infrastruktur merupakan salah satu indikator yang berhubungan dengan penerapan kewaspadaan universal. Sehingga diharapkan agar pihak rumah sakit selalu memonitoring ketersediaan sarana dan fasilitas di masing-masing unit agar dapat mendukung penerapan kewaspadaan standar dengan baik.
Analisis bivariabel menunjukkan bahwa terdapat hubungan yang bermakna antara informasi dan pelatihan dengan kepatuhan perawat dalam penerapan kewaspadaan standar, dimana responden yang mendapatkan informasi dan pelatihan secara kompeherensif akan lebih patuh 1,7 kali dibandingkan dengan responden yang mendapatkan informasi dan pelatihan secara kurang kompeherensif. Hasil penelitian ini konsisten dengan hasil penelitian Sugiyatno et al., (2014) yang diyakini ada hubungan yang signifikan antara pelatihan dengan kepatuhan perawat dalam penerapan kewaspadaan universal/standar ( $p=0,003)$. Didukung oleh teori model determinan perilaku kepatuhan untuk aplikasi perlindungan diri di tempat kerja oleh DeJoy (1996) yang mengungkapkan bahwa informasi dan pelatihan merupakan faktor organisasi yang turut memengaruhi kepatuhan terhadap kewaspadaan standar, sehingga diharapkan agar perkembangan ilmu yang dinamis serta informasi yang relevan dapat selalu disebarluaskan kepada pihak rumah sakit yang berkepentingan.

Berdasarkan hasil analisis bivariabel, tidak ada hubungan yang bermakna secara statistik antara umur responden dengan kepatuhan perawat dalam penerapan kewaspadaan standar $(p=0,768)$. Hasil penelitian ini sesuai dengan penelitian Runtu et al., (2013) di RSUP Prof. Dr. R. D. Kandou Manado yang mana tidak ada hubungan yang bermakna antara umur dengan perilaku perawat dalam penerapan universal precaution $(p=0,133)$, namun tidak konsisten dengan 
hasil penelitian Apriluana et al., (2016) yang diketahui bahwa ada hubungan yang signifikan antara usia dengan perilaku penggunaan APD, yang dalam hal ini merupakan komponen kewaspadaan standar dengan hasil uji statistik chi-square didapatkan

nilai $\mathrm{p}=0,006$. Menurut pandangan peneliti, perbedaan hasil tersebut bisa terjadi karena umur seseorang bukan satu-satunya yang dapat menentukan perilaku kepatuhan, karena bisa tergantung pada pendewasaan diri dan penyesuaian seseorang dengan lingkungan sekitarnya.

Berdasarkan analisis bivariabel pada variabel jenis kelamin menunjukkan tidak ada hubungan yang bermakna dengan kepatuhan perawat $(p=0,083)$. Hasil penelitian serupa ditemui pada penelitian Aung et al., (2017) mengenai penerapan kewaspadaan standar pada perawat di Myanmar menyatakan tidak terdapat hubungan antara jenis kelamin dengan penerapan kewaspadaan standar $(p=1,00)$. Hal ini didukung oleh Teori Health Belief Model dari Rosenstock \& Strecher (1997), bahwa jenis kelamin sebagai faktor sosiodemografi hanya sebagai penentu persepsi individu terhadap kerentanan, keparahan, keuntungan dan hambatan yang memiliki dampak secara tidak langsung terhadap perilaku individu.

Analisis bivariabel tidak menunjukkan adanya hubungan yang bermakna secara statistik antara tingkat pendidikan dengan kepatuhan perawat dalam penerapan kewaspadaan standar $(p=0,149)$. Hasil penelitian ini sejalan dengan yang dinyatakan Sagita et al., (2019) di Rumah Sakit Pemerintah Yogyakarta mengenai penerapan kewaspadaan standar dimana tingkat pendidikan tidak memiliki pengaruh yang signifikan dengan kepatuhan perawat dalam penerapan kewaspadaan standar $(p=0,128)$. Hal ini karena perawat yang bekerja di Rumah Sakit Umum, di Kota Denpasar baik yang berpendidikan D3 maupun S1 sudah mendapatkan pelatihan prosedur kewaspadaan standar, sehingga sebagian besar responden pada masing-masing jenjang pendidikan sudah patuh dalam menerapkan prosedur kewaspadaan standar.

Analisis bivariabel menunjukkan persepsi tentang risiko tidak ada hubungan yang bermakna dengan kepatuhan penerapan kewaspadaan standar $(p=0,279)$. Hasil penelitian ini serupa dengan penelitian Kartika \& Rahayu (2018) yang mendapatkan hasil tidak terdapat hubungan antara persepsi terhadap risiko dengan kepatuhan dalam penerapan kewaspadaan universal pada petugas kesehatan terhadap kejadian needle stick injury ( $\mathrm{p}=0,375)$. Hasil penelitian ini tidak sesuai dengan teori konsep Health Belief Model yang menyatakan bahwa individu memiliki kemungkinan melakukan pencegahan tergantung secara langsung pada ancaman yang dirasakan dan mempertimbangkan keuntungan dan kerugiannya (Machfoedz \& Suryani, 2007).

Analisis bivariabel menunjukkan bahwa tidak ada hubungan yang bermakna secara statistik antara hambatan dalam penerapan kewaspadaan standar 
dengan perilaku kepatuhan $(\mathrm{p}=0,779)$.

Hasil penelitian ini sejalan dengan penelitian Sagita et al., (2019) yang menyatakan tidak ada hubungan yang bermakna antara hambatan penerapan kewaspadaan standar dengan praktik penerapan kewaspadaan standar $(\mathrm{p}=0,876)$. Walaupun hasil analisis chi-square ini tidak menunjukkan hubungan yang bermakna, perlu diperhatikan kembali bahwa beberapa responden tidak mempunyai waktu yang cukup serta padatnya tugas sehari-hari menjadi penghalang untuk mengikuti pedoman kewaspadaan standar dalam melakukan tindakan keperawatan. Sehingga perlu diberikan pelatihan mengenai manajemen waktu yang baik bagi perawat agar lebih terampil memanajemen waktu dalam hal mengorganisir dan memprioritaskan setiap kegiatan. Dengan demikian, pekerjaan dapat dilakukan dengan efektif dan efisien sehingga memeroleh hasil pekerjaan yang berkualitas.

Analisis bivariabel pada variabel beban kerja juga menunjukkan tidak terdapat hubungan yang bermakna dengan kepatuhan perawat dalam penerapan kewaspadaan standar $(\mathrm{p}=0,734)$. Hasil penelitian ini konsisten dengan hasil penelitian Nurkhasanah (2014) mengenai kepatuhan perawat dalam penerapan kewaspadaan universal bahwa tidak ada hubungan yang bermakna antara beban kerja dengan kepatuhan penerapan kewaspadaan universal $(p=0,136)$. Berbeda dengan teori yang dari Smet (1994), dimana tingginya beban kerja dapat menyebabkan stress di antara perawat dan bidan sehingga dapat menyebabkan ketidakpatuhan terhadap kewaspadaan universal/standar. Hal ini bisa terjadi karena karakteristik unit kerja perawat serta jenis pasien yang dirawat yang berbeda-beda sehingga dapat memengaruhi variasi beban kerja perawat setiap saat.

\section{SIMPULAN}

Berdasarkan hasil pada penelitian ini, maka dapat ditarik beberapa kesimpulan, dimana berdasarkan karakteristik demografi responden, mayoritas berumur rentang usia pertengahan (30-39 tahun), berjenis kelamin perempuan, dan dengan tingkat pendidikan S1+Ners. Mayoritas responden sudah patuh dalam menerapkan kewaspadaan standar (59,21\%). Analisis bivariabel membuktikan terdapat hubungan yang bermakna antara faktor terkait pekerjaan yaitu pengetahuan $(p<0,05)$ dengan kepatuhan perawat dalam penerapan kewaspadaan standar. Selain itu, terdapat hubungan yang bermakna antara faktor organisasi yang meliputi iklim keselamatan, ketersediaan sarana dan fasilitas, serta informasi dan pelatihan $(p<0,05)$ dengan kepatuhan perawat dalam penerapan kewaspadaan standar. Ketersediaan sarana dan fasilitas merupakan variabel yang paling dominan berpengaruh terhadap kepatuhan perawat dalam penerapan kewaspadaan standar (adjusted $\mathrm{OR}=5,31$ ).

\section{SARAN}

Bagi pihak rumah sakit agar selalu menjadikan perlindungan pekerja terhadap pajanan penyakit infeksi sebagai 
hal yang harus diutamakan yang salah satunya melalui pemenuhan kebutuhan tersedianya sarana dan fasilitas yang berhubungan dengan penerapan kewaspadaan standar. Selain itu perlu diberikan pelatihan mengenai manajemen waktu yang baik bagi perawat agar lebih terampil memanajemen waktu dalam hal mengorganisir dan memprioritaskan setiap kegiatan, serta meningkatkan informasi dan pelatihan melalui pelaksanaan pendidikan dan pelatihan secara berkala mengenai kewaspadaan standar, penularan penyakit infeksi, dan prosedur pelaporan apabila terjadi kecelakaan kerja.

Bagi tenaga kesehatan khususnya perawat, perlu meningkatkan kewaspadaan terhadap adanya pajanan penyakit infeksi di rumah sakit dengan menerapkan prosedur kewaspadaan standar sesuai standar operasional prosedur yang sudah ada dan meningkatkan kerjasama dan koordinasi sebagai upaya dalam mengoptimalkan pencegahan dan pengendalian infeksi di unit kerja.

Bagi peneliti selanjutnya yang ingin mengambil penelitian serupa sebaiknya melakukan observasi langsung terhadap penerapan kewaspadaan standar yang dilakukan oleh responden serta observasi terhadap ketersediaan sarana dan fasilitas agar hasil yang didapatkan sepenuhnya sesuai dengan keadaan di rumah sakit.

\section{DAFTAR PUSTAKA}

Apriluana, G., Khairiyati, L., \& Setyaningrum, R. (2016). Hubungan Antara Usia, Jenis Kelamin, Lama
Kerja, Pengetahuan, Sikap Dan Ketersediaan Alat Pelindung Diri (APD) Dengan Perilaku Penggunaan Apd Pada Tenaga Kesehatan. Jurnal Publikasi Kesehatan Masyarakat Indonesia, 3(3), 82-87.

Aung, Sa. Sa.; Nursalam.; Yulis Setia Dewi. (2017). Factors Affecting The Compliance Of Myanmar Nurses In Performing Standard Precautions. Jurnal Ners Vol. 12 No. 1 April 2017: 1-8 Standard, 1-8.

CDC. (2007). Guideline for Isolation Precautions: Preventing Transmission of Infectious Agents in Healthcare Settings. (September), 33-53.

DeJoy, D. M. (1996). Theoretical models of health behavior and workplace selfprotective behavior. Journal of Safety Research, 27(2), 61-72.

DeJoy, D. M., Schaffer, B. S., Wilson, M. G., Vandenberg, R. J., \& Butts, M. M. (2004). Creating safer workplaces: Assessing the determinants and role of safety climate. Journal of Safety Research, 35(1), 81-90.

Efstathiou, G., Papastavrou, E., Raftopoulos, V., \& Merkouris, A. (2011). Factors influencing nurses' compliance with Standard Precautions in order to avoid occupational exposure to microorganisms: A focus group study. BMC Nursing, 10, 1-12. https://doi.org/10.1186/1472-6955-10-1 Gultom, A., Umboh, J. M. L., \& Polii, B. (2016). Faktor-Faktor Yang Berhubungan Dengan Penerapan Kewaspadaan Universal (Universal Precaution) Oleh Perawat Di Ruang 
Rawat Inap Penyakit Dalam (Irina C) RSUP. PROF. Dr. R. D. Kandau Manado. (Irina C), 29-42.

Kartika, R., \& Rahayu, R. S. R. (2018). Analisis Faktor Individu dan Faktor Penguat dengan Kepatuhan pada Kewaspadaan Universal di Layanan Kesehatan. Public Health Perspective Journal, 2(3), 206-214.

Kementerian Kesehatan RI. (2010). Keputusan Menteri Kesehatan Republik Indonesia Nomor: 1087/MENKES/SK/VIII/2010 Tentang Standar Kesehatan dan Keselamatan Kerja di Rumah Sakit. Kemenkes RI, 136.

Kementerian Kesehatan Republik Indonesia. (2017). Peraturan Menteri Kesehatan Republik Indonesia Nomor 27 Tahun 2017 Tentang Pedoman Pencegahan dan Pengendalian Infeksi di Fasilitas Pelayanan Kesehatan (pp. 1-14). pp. 1-14.

Krisnata, A. (2016). Faktor - Faktor Yang Berhubungan Dengan Praktik Universal Precautions Pada Perawat Dalam Upaya Pencegahan Risiko Healthcare Associated Infections ( HAIs ) Di Ruang Rawat Inap Rsud. Fakultas Keolahragaan Universitas Negeri Semarang.

Lantu, J., Abeng, T. D. ., \& Kandou, G. D. (2015). Analisis Penerapan Standard Precautions Oleh Perawat Di Rumah Sakit Bhayangkara Tk Iii Manado 98106. Retrieved from http://www.ejournalhealth.com/index .php/CH/article/view/111

Luo, Y., He, G. P., Zhou, J. W., \& Luo, Y. (2010). Factors impacting compliance with standard precautions in nursing, China. International Journal of Infectious Diseases, 14(12), e1106-e1114. https://doi.org/10.1016/j.jiid.2009.03.0 37

Machfoedz, I., \& Suryani, E. (2007). Pendidikan Kesehatan Bagian dari Promosi Kesehatan. Yogyakarta: Fitramaya.

Mapanawang, S., Pandelaki, K., \& Panelewen, J. (2017). Hubungan Antara Pengetahuan, Kompetensi, Lama Kerja, Beban Kerja Dengan Kejadian Tertusuk Jarum Suntik Pada Perawat Di Rsud Liun Kendage Tahuna. Jurnal EMBA: Jurnal Riset Ekonomi, Manajemen, Bisnis Dan Akuntansi, 5(3), 4336-4345.

Nurkhasanah, U. S. (2014). Kepatuhan

Perawat Dalam Penerapan Kewaspadaan Universal Di Rumah Sakit Dokter Kariadi Semarang Tahun 2013. 222-228.

Wansuzusino, W. (2019). Factors Affecting Indonesian Nurse Behavior in Applying Universal Precaution. South East Asia Nursing Research, 1(2), 88. https://doi.org/10.26714/seanr.1.2.201 9.88-94

Yotlely, A. S. (2019). Analisis Faktor Yang Berhubungan Dengan Kepatuhan Perawat Dalam Penerapan Kewaspadaan Standar Di RSUD Piru. Fakultas Keperawatan Universitas Airlangga [Skripsi].

Yuliana, C. (2012). Kepatuhan Perawat Terhadap Kewaspadaan Standar di RSKO Jakarta. Universitas Indonesia, Depok [Skripsi]. 